\title{
Electrical and mechanical aspects of left atrial activity
}

\author{
H. J. N. Bethell ${ }^{1}$ and P. G. F. Nixon \\ From the Cardiac Department, Charing Cross Hospital, Fulham Palace Road, London
}

The relation between abnormalities of the $P$ wave of the electrocardiogram and the left ventricular filling pattern as shown by apex cardiography has been investigated in 76 subjects with either normal hearts or hypertensive/ischaemic heart disease. Deteriorating left ventricular function, as shown by apex cardiography, was associated with increasing negativity of the $P$ wave 'terminal force' in lead VI. There was a significant association between the amplitude of the ' $a$ ' wave of apex displacement and the $P$ wave 'terminal force' in patients without a pathological third heart sound.

Abnormalities of the $\mathbf{P}$ wave of the electrocardiogram are common in diseases of the left side of the heart (Martins de Oliveira and Zimmerman, 1959; Davies and Ross, 1963; Braunwald et al., 1964; Morris et al., 1965; Romhilt and Scott, 1972). Their relation to various disorders of left atrial function has been examined; e.g. to abnormal left atrial pressure (Morris et al., 1964; Kasser and Kennedy, 1969), volume (Abildskov, 1957; Arvidsson, Zazo, and Grewin, 1960; Arevalo, Spagnuolo, and Feinstein, 1963; Morris et al., 1964; Gooch et al., 1966; Reynolds, 1967; Saunders et al., 1967; Kasser and Kennedy, 1969), and muscle mass (Pirani and Langendorf, 1949; Mazzoleni et al., 1964; Romhilt et al., 1972). However, it is clear that the $\mathbf{P}$ wave can be normal when these disorders are present and abnormal when they are absent (Kaufman and Scott, 1949; Morris et al., 1964).

An important indicator of left heart disease, which gives information about left atrial activity, is provided by the diastolic filling movements of the left ventricle. These may be recognized at the bedside and recorded by the technique of apex cardiography. There is a reciprocal relation between the early diastolic rapid filling wave of the left ventricle and the presystolic contribution from atrial contraction - the atrial beat or ' $a$ ' wave (Shah and $\mathrm{Yu}$, 1969; Cohn et al., 1971; Taylor and Nixon, 1972). In health the rapid filling wave is prominent and the ' $a$ ' wave small (Fig. $I$ ). With deteriorating left heart function, the rapid filling wave wanes while the ' $a$ ' wave waxes and is frequently accompanied by an atrial sound (Fig. 2 and 3 ). With more severe

Received 29 November 1973.

${ }^{1}$ In receipt of a Research Fellowship from the Board of Governors of Charing Cross Hospital. heart 'failure', the rapid filling wave returns and the ' $a$ ' wave diminishes again (Fig. 4 and 5).

The purpose of this study was to seek any relation which might exist between these filling patterns of the left ventricle and abnormalities of the $P$ wave of the electrocardiogram.

\section{Patients and methods}

Electrocardiographic and apex cardiographic studies were made on 76 patients who had either normal hearts or hypertensive/ischaemic heart disease. There were no cases of valvar or congenital heart disease and all were in sinus rhythm. A 12-lead electrocardiogram was performed in each case, using a Cambridge VSIII or Transrite 4 electrocardiograph. The following measurements, averaged over 5 consecutive complexes, were made in each case.

I) The $\mathbf{P}$ wave 'terminal force' in lead VI (Morris et al., 1964). This is the product of the duration and amplitude of the terminal portion of the $P$ wave in lead VI. It is not more negative than -0.030 $\mathrm{mm} . \mathrm{sec}$ in normal subjects, and rarely more negative than $-0.020 \mathrm{~mm}$.sec.

2) The duration of the $P$ wave in lead II.

3) The presence of notching of the $P$ wave, with a peak to peak separation of more than $0.03 \mathrm{sec}$, in any lead (Lepeschkin, I95I).

4) The $P$ axis in the frontal plane.

5) The 'Macruz index' (Macruz, Perloff, and Case, 1958). This is the ratio between the $P$ wave duration and the PR segment duration. The normal Macruz index lies between $\mathrm{I} \cdot 0$ and $\mathrm{I} \cdot 6$.

Apex cardiograms were performed in each case, using a technique and apparatus described elsewhere (Nixon, Hepburn,and Ikram, 1964). In each case, the ratio of the ' $a$ ' wave amplitude to the total diastolic displacement (' $\mathrm{a}$ '/O-A ratio) was measured and averaged over 5 con- 
secutive beats. The apex cardiogram patterns were classified according to whether this ratio was physiological, i.e. less than 40 per cent (group $O$ ); whether the ' $a$ ' wave was waxing (groups $I$ and 2 ) or waning (groups 3 and 4):

Group O: (Fig. I) The 'a' wave height was less than 40 per cent of the total (O-A) diastolic excursion, in the absence of overt heart failure.

Group I: (Fig. 2) The ' $a$ ' wave height was 40 per cent to 69 per cent of the diastolic excursion.

Group 2: (Fig. 3) The 'a' wave height was 70 per cent or more of the diastolic excursion.

Group 3: (Fig. 4) The ' $a$ ' wave height was 40 per cent or more of the diastolic excursion, and there was a brisk rapid filling wave, usually accompanied by a third heart sound. There was clinical evidence of severe heart disease in all these patients.

Group 4: (Fig. 5) The 'a' wave height was less than 40 per cent of the diastolic excursion, with a brisk rapid filling wave usually accompanied by a third heart sound, in the presence of clinically evident cardiac failure.

The $\mathbf{P}$ wave characteristics for each of these apex cardiographic groups were compared. The $\mathbf{P}$ wave terminal force was compared with the ' $a$ '/O-A ratio for the subjects in groups $\mathrm{O}$ to 4 .

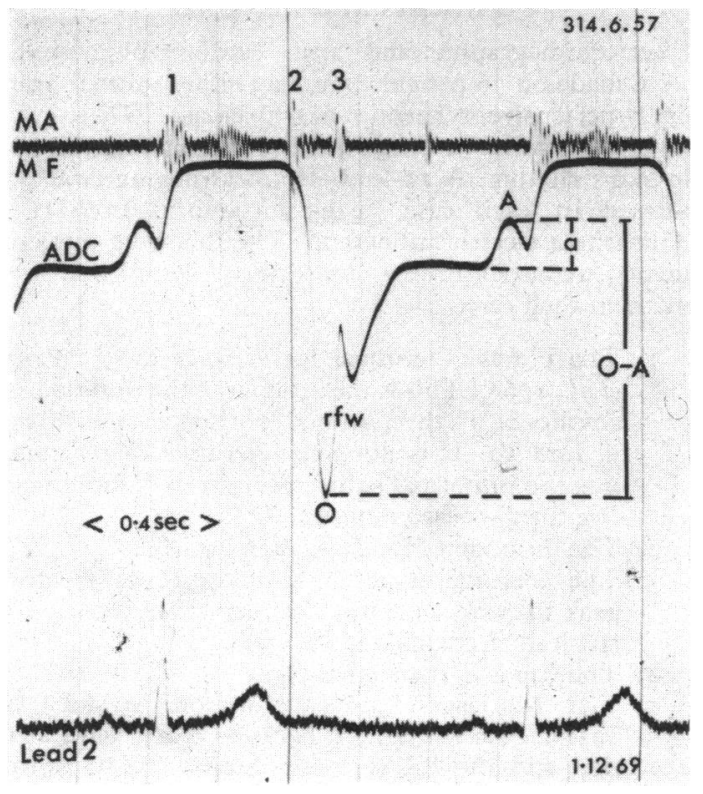

FIG. I Group O. Normal apex cardiogram ( $A D C)$, mitral area medium frequency phonocardiogram $(M A M F)$, and lead II of the electrocardiogram. The ' $a$ ' wave amplitude (' $a$ ') is less than 40 per cent of the total diastolic excursion $(O-A)$.

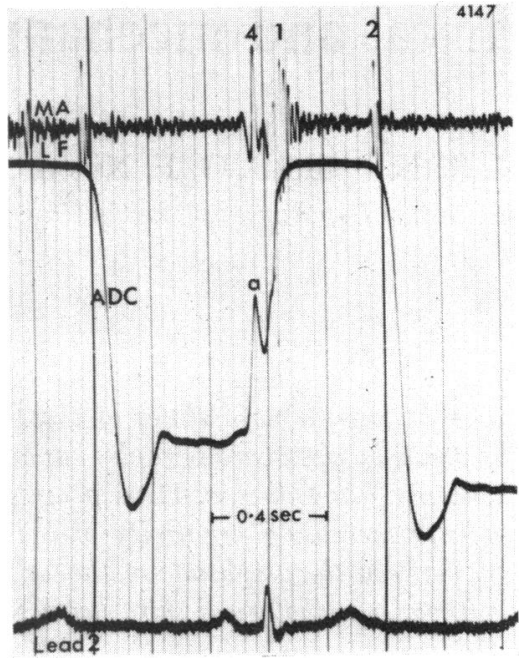

FIG. 2 Group I. The ' $a$ ' wave amplitude is between 40 and 69 per cent of the diastolic excursion.

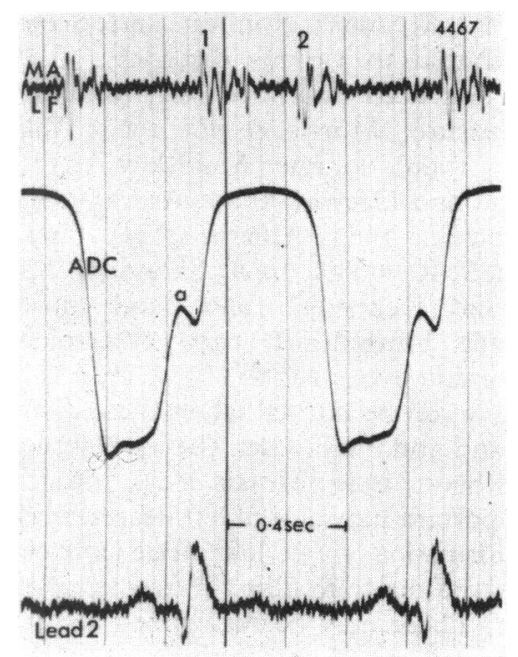

FIG. 3 Group 2. The ' $a$ ' wave amplitude is 70 per cent or more of the total diastolic excursion.

\section{Results}

There were 26 patients in group $O, 22$ in group $I$, 14 in in group 2, 9 in group 3 , and 5 in group 4. The mean $P$ wave measurements in each group are shown in the Table.

The individual $P$ wave 'terminal force' in lead VI in each member of each group is shown in Fig. 6. This 'terminal force' increases in negativity from $-0.006 \mathrm{~mm} . \mathrm{sec}$ in group $\mathrm{O}$, through $-0.01 \mathrm{I}$ 


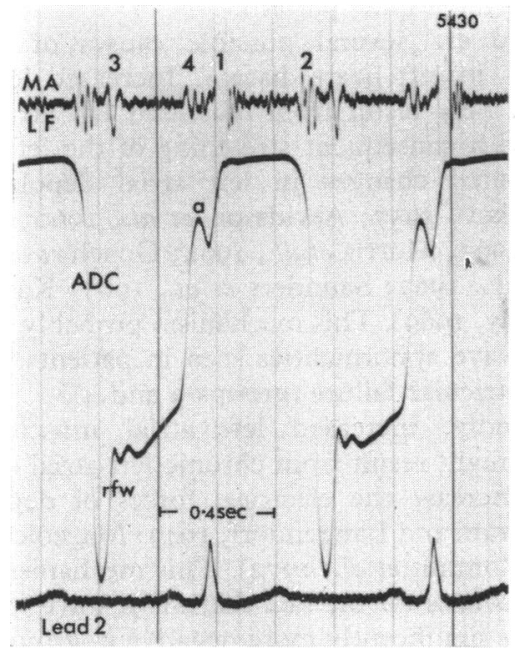

FIG. 4 Group 3. The ' $a$ ' wave amplitude is 40 per cent or more of the total diastolic excursion, there is a brisk rapid filling wave and third heart sound. There is clinical evidence of severe heart disease.

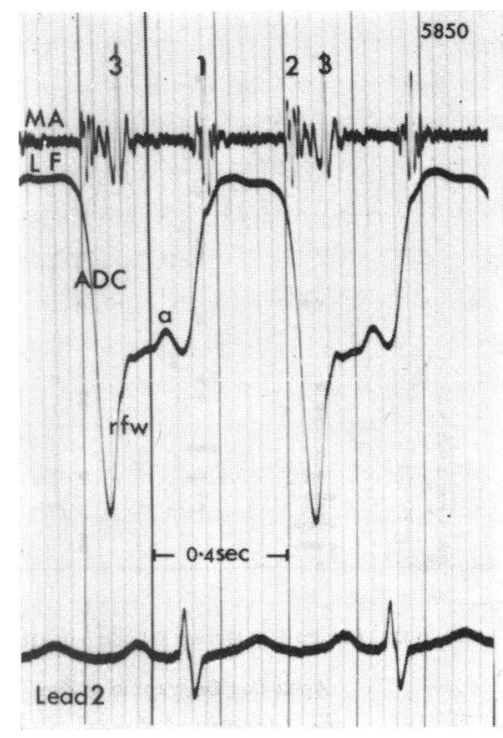

FIG. 5 Group 4. The ' $a$ ' wave amplitude is less than 40 per cent of the diastolic excursion, there is a brisk rapid filling wave and third heart sound, in the presence of clinically obvious left ventricular failure.

TABLE Mean values of $P$ wave variables in each apex cardiographic group

\begin{tabular}{lccccc}
\hline & $\begin{array}{l}\text { Group } 0 \\
n=26\end{array}$ & $\begin{array}{l}\text { Group I } \\
n=22\end{array}$ & $\begin{array}{l}\text { Group 2 } \\
n=14\end{array}$ & $\begin{array}{l}\text { Group 3 } \\
n=9\end{array}$ & $\begin{array}{l}\text { Group 4 } \\
n=5\end{array}$ \\
\hline $\begin{array}{l}\text { P wave terminal force } \\
\text { (mm.sec) in lead VI }\end{array}$ & -0.006 & -0.011 & -0.027 & -0.025 & -0.055 \\
P wave duration (sec) & \pm 0.007 & \pm 0.010 & \pm 0.019 & \pm 0.017 & \pm 0.017 \\
in lead II & 0.10 & 0.10 & 0.11 & 0.10 & 0.12 \\
Notching incidence & $12 \%$ & $27 \%$ & $29 \%$ & $67 \%$ & $40 \%$ \\
Axis & $52^{\circ}$ & $50^{\circ}$ & $51^{\circ}$ & $41^{\circ}$ & $60^{\circ}$ \\
Macruz index & 1.7 & 2.0 & 1.7 & 1.8 & 2.1 \\
\hline
\end{tabular}

Note: There is increasing negativity of the $\mathrm{P}$ wave terminal force in lead VI with deteriorating heart function, except in Group 3. There is no relation between the P wave duration in lead II (P II), the P wave axis or the Macruz index, and the apex cardiographic group.

mm.sec in group $1,-0.027 \mathrm{~mm} . \mathrm{sec}$ in group 2, $-0.025 \mathrm{~mm}$. sec in group 3 to $-0.055 \mathrm{~mm}$. sec in group 4. Applying Student's ' $t$ ' test to these figures shows that the $\mathbf{P}$ wave 'terminal force' in lead VI in group $O$ is significantly less negative than in group 2 ( $P<0.001)$, group $3(\mathbf{P}<0.001)$, and grøup $4(P<0.001)$. The difference between the $P$ wave 'terminal force' in group $\mathrm{O}$ and group $\mathrm{I}$ is not significant.

The incidence of $P$ wave notching increases from 12 per cent in group $O$ to 67 per cent in group 3, but paradoxically decreases in group 4. The duration of the $\mathbf{P}$ wave in lead II, the $\mathbf{P}$ wave axis, and the Macruz index do not show any definite correlation with the apex cardiographic pattern.

\section{Discussion}

The apex cardiegram, by demonstrating the filling pattern of the left ventricle, can give a guide to the work done by the left atrium and the mean left atrial pressure (Shah and Yu, 1969; Cohn et al., I97I; Taylor and Nixon, 1972). The group $O$ pattern (Fig. I) is that seen in the normal heart. The bulk of left ventricular filling appears to occur during the rapid filling and slow filling phases, with 


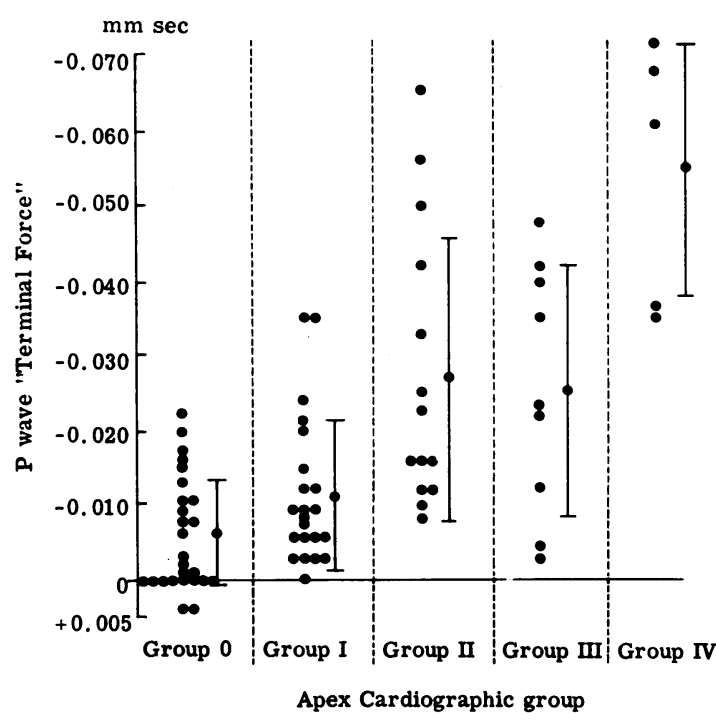

FIG. 6 The $P$ wave 'terminal force' in lead $V_{I}$ for each member of each group. The means and standard deviations are included.

only a small contribution from atrial systole. When the left ventricle is diseased, it may fill less readily in early diastole, with diminution of the rapid filling wave, while the contribution of left atrial systole increases and produces a prominent ' $a$ ' wave, which usually is accompanied by an atrial sound (Group $\mathrm{I}$, Fig. 2). The mean left atrial pressure in these patients is normal, though the peak left atrial pressure, the amplitude of the ' $a$ ' wave of the left ventricular pressure curve, and the left ventricular end-diastolic pressure may all be raised. In group 2 (Fig. 3) the ' $a$ ' wave enlargement, both of the apex cardiogram and of the ventricular pressure curve, is greater, but the mean left atrial pressure is still normal. When the left ventricle goes into clinical failure, and the mean left atrial pressure rises, there is a return of early diastolic rapid filling, often accompanied by a third heart sound, with a diminution of the ' $a$ ' wave (group 3, Fig. 4). When the mean left atrial pressure is $20 \mathrm{mmHg}$ or more, the ' $a$ ' wave diminishes further, with loss of the atrial sound, while the rapid filling wave and third sound become even more prominent (group 4, Fig. 5).

This study demonstrates some association between the size of the $P$ wave 'terminal force' in lead VI and the diastolic filling pattern of the left ventricle as shown by apex cardiography. It also shows a tendency for $\mathrm{P}$ wave notching to become more frequent with deteriorating heart function as measured by the apex cardiographic pattern. It is surprising that the other parameters of the $P$ wave which were measured - its duration, axis, and Macruz index - showed no association with the apex cardiographic pattern.

There are several possible causes of $P$ wave changes in left heart disease. Increased left atrial volume may result from increased left atrial pressure, with consequent stretching of the left atrium and spatial changes in left atrial depolarization (Abildskov, 1957; Arvidsson et al., 1960; Arevalo et al., 1963; Morris et al., 1964; Gooch et al., 1966; Reynolds, 1967; Saunders et al., 1967; Kasser and Kennedy, 1969). This mechanism probably explains the $\mathbf{P}$ wave abnormalities seen in patients in overt left ventricular failure (groups 3 and 4 ).

Secondly, increased left atrial muscle mass, which might result from chronic left atrial overload could increase the electrical forces of depolarization (Pirani and Langendorf, 1949; Mazzoleni et al., 1964; Romhilt et al., 1972). This mechanism probably accounts for the fact that the $P$ wave 'terminal force' is significantly more negative in group 2 than in group $\mathrm{O}$, and may therefore be an important cause of $\mathbf{P}$ wave changes in cases of hypertensive/ ischaemic heart disease without left ventricular failure.

Finally, degenerative changes in the left atrial muscle which result from disease of the coronary vessels supplying the atrium (Pirani and Langendorf, 1949; Liu, Greenspan, and Piccirillo, I96I) may cause altered patterns of atrial depolarization and interatrial block (Bradley and Marriot, 1956). This mechanism probably accounts for the $P$ wave abnormalities seen in some patients with early coronary heart disease without other evidence of left atrial involvement (Bethell and Nixon, 1972). It may play a part, also, in the production of $P$ wave changes in overt left ventricular failure, since increased left atrial pressure might reduce the blood supply to the atrial muscle, particularly distal to a coronary stenosis.

\section{References}

Abildskov, J. A. (1957). A quantitative study of the electrocardiographic effects of atrial enlargement. American Heart fournal, 53, 55.

Arevalo, A. C., Spagnuolo, M., and Feinstein, A. R. (1963). A simple electrocardiographic indication of left atrial enlargement. Fournal of the American Medical Association, $185,358$.

Arvidsson, H., Zazo, S., and Grewin, K. E. (1960). Correlation between mitral $P$ wave and left atrial volume determined by angiocardiography. Cardiologia, 37, 255 .

Bethell, H. J. N., and Nixon, P. G. F. (1972). P wave of electrocardiogram in early ischaemic heart disease. British Heart fournal, 34, 1 I 70.

Bradley, S. M., and Marriott, H. J. L. (1956). Intra-atrial block. Circulation, 14, 1073. 
Braunwald, E., Lambrew, C. T., Rockoff, S. D., Ross, J., and Morrow, A. G. (1964). Idiopathic hypertrophic subaortic stenosis. Circulation, 30, Suppl. 4, 3.

Cohn, P. F., Vokonas, P. S., Williams, R. A., Herman, M. V., and Gorlin, R. (197I). Diastolic heart sounds and filling waves in coronary artery disease. Circulation, 44, 196.

Davies, L. G., and Ross, I. P. (1963). Abnormal P waves and paroxysmal tachycardia. British Heart fournal, 25, 570.

Gooch, A. S., Calatayud, J. B., Rogers, J. B., and Gorman, P. A. (1966). Analysis of the $P$ wave in severe aortic stenosis. Diseases of the Chest, 49, 459.

Kaufman, J., and Scott, R. C. (1949). Pathologic and electrocardiographic study of the auricles. Fournal of Laboratory and Clinical Medicine, 34, 1617.

Kasser, I., and Kennedy, J. W. (1969). Relationship of increased left atrial volume and pressure to abnormal $P$ waves on the electrocardiogram. Circulation, 39, 339.

Lepeschkin, E. (195I). Modern Electrocardiography. Williams and Wilkins, Baltimore.

Liu, C. K., Greenspan, G., and Piccirillo, R. T. (I96I). Atrial infarction of the heart. Circulation, 23, 33I.

Macruz, R., Perloff, J. K., and Case, R. B. (1958). A method for the electrocardiographic recognition of atrial enlargement. Circulation, 17, 882.

Martins de Oliveira, J., and Zimmerman, H. A. (1959). Auricular overloadings. Electrocardiographic analysis of I93 cases. American fournal of Cardiology, 3, 453.

Mazzoleni, A., Wolff, R., Wolff, L., and Reiner, L. (1964). Correlation between component cardiac weights and electrocardiographic patterns in 185 cases. Circulation, 30, 808.

Morris, J. J., Dunlap, W. M., Thompson, H. K., McIntosh, H. D., and Estes, E. H. (1965). P-wave analysis in the electrocardiographic diagnosis of left ventricular hypertrophy (abstract). Circulation, 32, Suppl. 2, I 54.
Morris, J. J., Estes, E. H., Whalen, R. E., Thompson, H. K., and McIntosh, H. D. (1964). P-wave analysis in valvular heart disease. Circulation, 29, 242.

Nixon, P. G. F., Hepburn, F., and Ikram, H. (1964). Simultaneous recording of heart pulses and sounds. British Medical fournal, $1,1169$.

Pirani, C. L., and Langendorf, R. (1949). Pathology of the cardiac atria. An anatomic-electrocardiographic correlation based on a study of 85 human hearts (abstract). American Heart fournal, 37, 663.

Reynolds, J. L. (1967). The electrocardiographic recognition of left atrial enlargement in childhood. American Heart fournal, 74, 179.

Romhilt, D. W., Bove, K. E., Conradi, S., and Scott, R. C. (1972). Morphologic significance of left atrial involvement. American Heart fournal, 83, 322.

Romhilt, D. W., and Scott, R. C. (1972). Left atrial involvement in acute pulmonary edema. American Heart fournal, 83, 328.

Saunders J. L. Calatayud, J. B., Schulz, K. J., Maranhao, V., Gooch, A. S., and Goldberg, H. (1967). Evaluation of ECG criteria for $\mathrm{P}$ wave abnormalities. American Heart fournal, 74, 757.

Shah, P. M., and Yu, P. N. (1969). Gallop rhythm. Hemodynamic and clinical correlation. American Heart fournal, 78, 823.

Taylor, D. J. E., and Nixon, P. G. F. (1972). Assessment of left ventricular function after myocardial infarction. British Heart fournal, 34, 905.

Requests for reprints to Dr. P. G. F. Nixon, Cardiac Department, Charing Cross Hospital, Fulham Palace Road, London W6 8RF. 